\title{
DISCUSSION
}

\section{ILLNESS: NARRATIVES, IMAGERY, AND POLITICS}

\section{Remarks on a Seminar, an Exhibition, and a Conference}

\author{
Daniele Monticelli \\ Professor of Semiotics and Translation Studies \\ School of Humanities, Tallinn University, Estonia \\ daniele.monticelli@tlu.ee
}

\begin{abstract}
The article uses the review of a seminar, an exhibition, and a graduate conference, which took place at Tallinn University in the 2020-2021 academic year, as an occasion to reflect on the different ways in which illness has been represented in literature, the arts, and film across the history of Western culture. The specific focus of the article is on the theoretical contribution of the humanities to a more complex and adequate understanding of the phenomenon of illness. The study of illness narratives reveals different patterns and strategies of constructing the illness experience into a coherent and meaningful story, but also the resistance that the disruptive impact of illness on our everyday lives poses to narrativisation. The complex historical imagery which endows the biological fact of being sick with additional cultural and social meaning has also to be critically investigated in the humanities and social sciences. Metaphors about illness and the use of illness as a socio-political metaphor have often had a nefarious impact on sick people as well as entire social groups and communities. This is why the article also considers illness in its relations with politics and power and describes various attempts to empower sick people in their relations with medical institutions and their social environment. The article ends with a review of the "Illness: Narratives, Imagery, Politics" graduate conference (27-28 January 2021), which is a good illustration of the many literary and artistic works and of the plurality of methods that can be used in the study of the illness phenomenon from a humanities perspective.
\end{abstract}

Keywords: illness and metaphor, illness narratives, medical humanities, representation of suffering, the illness: narratives, imagery, politics conference

Since spring 2020 we have been living in a global state of emergency that has deeply invested all the aspects of our personal and social life. Illness, which used to be in our experience rather a private and intimate issue, has suddenly become something that requires our common effort not only in terms 
of behaviour, but also of feelings and cognition. And yet, this should not have come as a surprise, as in the past ten years we have been constantly warned of the possibly devastating effects of new emergent diseases such as Ebola, SARS, swine and avian flu, etc. The HIV pandemics is in many respects still with us, and while it has never had such a comprehensive social impact as Covid-19, ${ }^{1}$ it has nevertheless profoundly influenced our social and cultural imagination as well as changed our sexual behaviour.

The HIV pandemic and concerns about new emergent diseases in our globalised world have been accompanied by an unprecedented boom in references to disease and medicine in literature, movies, and popular culture since the last decade of the 20 th century. At a moment when medicine continues to progress at high speed together with our life expectancy, we are particularly at pains in the attempt to make sense of illness and its consequences for individuals and societies. And the imagination of present or future pandemics tends to merge with the general apocalyptic attitude, which seems to increasingly structure our feelings at the beginning of the 21st century with its sense of never-ending crisis (terrorism, economy, refugees, etc.) and impending final catastrophe (ecological breakdown).

In the 2020 autumn semester, I organised a seminar at which students of different MA curricula of Tallinn University's School of Humanities had the opportunity to discuss many of the issues that the present health and social crises engender from the perspective of the humanities. This means investigating how culture (literature, the arts, film) has represented and interpreted the universe of illness in its different aspects. In order to do so, we took as our material a long series of works in different media. As for literature, we read texts stretching from the description of the 5th century BC plague of Athens by Greek historian Thucydides to the classics of illness in 20th-century literature, such as Albert Camus's The Plague and Thomas Mann's The Magic Mountain, as well as individual illness narratives published just a couple of years ago (e.g. Porochista Khakpour's Sick: A Memoir).

The movies included, among many others, Ingmar Bergman's The Seventh Seal (1957), Milos Forman's One Flew Over the Cuckoo's Nest (1975), Lars Von Trier's Melancholia (2011), and Michael Haneke's Amour (2012). Artworks spanned from Albrecht Dürer's engraving Melancholia (1514) to contemporary artists' photographs and video art inspired by the AIDS epidemic.

\section{NARRATIVES, IMAGERY, POLITICS}

The conceptual framework of the seminar was mirrored in its title - "Illness: Narratives, Imagery, Politics". We approached it with the help of theoretical texts that offered us interpretative tools from different disciplines of the 
humanities and social sciences with a particular focus on the rapidly growing field of the medical humanities.

Illness marks a disrupting interruption in the ways of our 'normal' life with important consequences for our perception of ourselves and our social status. As Virginia Woolf claims in her beautiful essay "On Being Ill”, illness brings about a "tremendous spiritual change" (Woolf 1926: 32); while we are ill, we cease to be "soldiers in the army of the upright; we become deserters" (ibid.: 37). If, on the one hand, the illness experience corresponds with a "loss of self" (Charmaz 1983), on the other hand it opens the gates to alternative existential dimensions and temporalities, a "world of illness" as opposed to the "mundane" (Radley 1999: 785). This is why the different ways in which we tell illness and make it into a story play a crucial role in our understanding of the illness phenomenon as well as the cure process and its results. Narrative has long been an important component of the biomedical logos with its emphasis on the patient's HPI ('history of the present illness') and the anamnesis-diagnosis-prognosis articulation of the three temporal dimensions of the illness and cure processes. More recently, the academic emergence of the medical humanities has directed the attention of scholars to the ways in which patients themselves construct their illness narrative - how this helps or hinders the recovery process and the tensions that the clash of incompatible stories may generate in the relations between the patient and the medical institution.

Our stories can construct illness into a teleological and meaningful experience or, on the contrary, be deranged by the meaningless disorder of the illness experience. Arthur W. Frank (1995) classically distinguished three different "storylines" in illness narratives: 'restitution' ("I was heathy, I am sick, but I will be better again"), reflecting the "modernist expectation that for every suffering there is a remedy" (Whitehead 2005: 3); 'chaos' ("I will never be well again"), which describes the sufferer as "sucked into the undertow of illness" (Frank 1995: 97); and 'quest', which recounts illness as an existential opportunity for change, a transformative journey giving us access to a knowledge that remains barred to healthy people. Lars-Christer Hyden rather focuses on the relations between narrator, narrative, and illness. On this basis he distinguishes between 'illness as narrative', in which the narrator tells his or her personal experience and "makes it possible to integrate the symptoms and consequences of the illness into a new whole" (Hyden 1997: 54), and "narrative about illness', in which knowledge and ideas about illness are conveyed by other people such as doctors. While most of the cultural representations of illness have traditionally been 'narratives about illness', in which illness was narrated from an external perspective, since the late 20th century we have witnessed a proliferation of autobiographical illness narratives (Hawkins 1999), which the new narrative forms offered by digital technology (blogging, YouTubing, etc.) 
have exponentially increased. Hyden's third category is 'narrative as illness', which describes situations in which "a narrative, or an insufficient narrative generates illness" (Hyden 1997: 55), i.e., the failure to structure the illness experience through narrative becomes the very cause of suffering.

Frank's and Hyden's categorisations of illness narrative are based on a quite traditional understanding of narrative as synonymous with verbal expression, linearity, and coherence. For this kind of narrative the body is, as Woolf (1926: 32) claims, "a sheet of plain glass through which the soul looks straight and clear"; on the contrary, in illness the body becomes opaque, its "daily drama" (ibid.: 33) escaping the rationalising grip of the soul. Stella Bolaki (2016) consequently claims that the traditional understanding of narrative is challenged by illness narratives and must consequently be replaced. She advocates an understanding of narrative in which stories are 'embodied' and 'improvised' rather than told. This does not lead to 'chaos' (Frank) or 'insufficiency' (Hyden); rather, it might be, in many cases, the only available way to 'narrate' the illness experience. This is particularly true when the medium of illness narrative is not literature, but other artistic forms such as photography, video art, sculpture, performances, etc.

A related and huge topic, which has been extensively explored in trauma and memory studies, is the ethical aspects which the aesthetisation of illness in the representation of one's own suffering or the suffering of others, unavoidably raises. In this respect Bolaki (2016: 11) stresses the need to distinguish between the positive pluralism, ambivalence and polyvalence of aesthetic practices that deal with illness and the reductive and homogenising aesthetisation of the illness experience.

It is interesting to observe that the narrativisation of the illness experience is not limited to the individual level (be it from an internal or external perspective), but also directly includes collective illness experience such as epidemics. In the history of Western culture narrative has played an important role in the attempt to construct a religious and social explanatory framework for the interpretation of the illness phenomenon. Two grounding masterpieces of Western epic and drama, Homer's Iliad and Sophocles' Oedipus Rex, start with descriptions of an epidemic sent by the gods to punish the community for the moral trespasses of its sovereign. Thucydides and Lucretius have left us memorable depictions of the plague of Athens ( $430 \mathrm{BC}$ ), and Giovanni Boccaccio of the devastating Black Death that struck Asia and Europe in the mid-1300s. Alessandro Manzoni dedicated two chapters of his historical novel The Betrothed to the description of the 1630s Italian plague while Daniel Defoe wrote an entire semi-documentary journal of the London 'plague year' of 1665. In Albert Camus's The Plague (1947) the fictional story of the plague of Oran becomes 
a humanistic reflection on evil, solidarity, and engagement. Since the 1990s a long series of popular catastrophe movies - for example, Wolfang Petersen's Outbreak (1995), Steven Soderbergh's Contagion (2011), Marc Forster's World War Z (2013), and the recent Russian TV series To the Lake (2019), to mention just a few - have rethought the epidemic narrative in the context of our globalised and ultra-connected world.

From a scholarly perspective, Charles E. Rosenberg (1989: 2) has claimed that "as a social phenomenon, an epidemic has a dramaturgic form", in which the 'progressive revelation' slowed down by politico-economic interests and fear (Act 1) is followed by recognition of the calamity and the creation of an explanatory framework for the 'management of randomness' (Act 2). The managing of response to epidemics, argues Rosenberg, can "serve as a vehicle for social criticism as well as a rationale for social control" (ibid.: 6), as is clearly evident in the case of the HIV epidemic, to which Rosenberg refers, as well as the Covid-19 pandemic that we are currently experiencing. Act 3 of Rosenberg's narrative deals with 'negotiating public response' to the epidemic, the complexity and tensions of which we know all too well. The epilogue to epidemic narratives always relates the lasting effect and the lessons learned. In her book Contagion: Cultures, Carriers, and the Outbreak Narrative, Priscilla Wald similarly describes what she calls the "outbreak narrative", defined as the way the media, literature, and movies narrate epidemic disease emergence in the "spaces and interactions of global modernity" (2008: 2). In the same way that I stressed above the performative effect of individual illness narratives on sick people, Wald stresses the performative effect of collective outbreak narratives on 'sick' societies: "as they [the outbreak narratives] disseminate information, they affect survival rates and contagion routes. They promote or mitigate the stigmatizing of individuals, groups, populations, locales (regional and global), behaviours, and lifestyles, and they change economies" (ibid.: 3).

Along with illness narratives, the works analysed in our seminar during the 2020 autumn semester exposed a complex cultural and social imagery in which the biological fact of being sick acquires additional cultural and social meaning, sometimes coinciding with dangerous alterity, impurity, decay, and sometimes with a different and privileged human condition. Susan Sontag's works $(1978,1989)$ are probably the best-known critical attempts to study the uses of illness (tuberculosis, cancer, and AIDS) as a 'figure' or 'metaphor'. Metaphors are, on the one hand, used to describe the causes, development, and consequences of diseases, as can be easily observed in many of the epidemic narratives mentioned above; on the other hand, diseases themselves become scary and harmful metaphors used to characterise many other aspects of our social life, such as, for instance, politics. 
It is therefore not by chance that Sontag ends her first book on illness and metaphor with an analysis of the use of disease imagery in the political rhetoric of the modern age. The understanding of politics in terms of a healthy vs pathological process is as old as Ancient Greek medicine and philosophy (see Hope \& Marshall 2004 [2000]). While the direct parallel between the order of the psyche and the order of the polis was established by Plato in his Politeia, the comparison between the biological body and the political order took more precise shape since the Middle Ages when the sovereign started to be represented as the personification of what scholars called the 'body politic', i.e., state and society as a whole. The most famous illustration of this idea can be found on the cover of Thomas Hobbes' Leviathan (1651), where the 'body politic' is represented as a giant body made up by the countless tiny bodies of subjects and the big head of the crowned sovereign. If society is a political body, it is subject to illness, which in the imagination of political thinkers tends to mean a loss of internal harmony, with civil strife menacing society with disorder, chaos, and the eventual dissolution of the 'body politic' (see Bertman 1978). Political enemies and opposed ideologies thus become diseases (from cancers to viruses) which need to be fought and cured by cordon sanitaires, purification, amputation, etc. of the sick and infected body parts in order to restore the harmony and unity (health) of the body politic. Illness, war, and politics are perversely entangled in the modern imagery with nefarious consequences for our ways of understanding and treating medical as well as social issues. The aim of Sontag's analysis is to expose and criticise the "lurid stereotypes" (1989: 46) that transform diseases into sources of social discrimination, militarisation of public discourse, authoritarian politics, etc.

Another important aspect of the relations between illness and power has been investigated by Michel Foucault in his study of the birth of the clinic (Foucault 2003). According to Foucault, the birth of modern medicine as a separate field of knowledge goes through the institutionalisation of the clinic and the new power relations that it establishes between the doctor and the sick. The "medical gaze" of modern biomedicine sanctions the unbridgeable hiatus between the knowledge of the doctors who see, understand, decide, and intervene, and the passivity of the sick, who cannot but trust and submit to the power of the knowledge that remains inaccessible to them. Alan Radley (1999: 783) describes the result of this submission as the "sufferer's sense of alienation and colonization by medicine".

In his book Eros and Illness, David Morris challenges the power of the biomedical logos with the opposite concept of 'medical eros'. Medical eros "encompasses all the various emotional, psychological, and personal implications of desire" (Morris 2017: 8) in the field of human health and illness; it connects with the uncertainties, lack of knowledge and control, disordered passions that 
characterise the inner life and lived experience of sick people and mainly pass unrecognised by biomedicine that ignores the role of desire in illness. Morris advocates a tense collaboration (concordia discors) between medical logos and medical eros, citing the example of the "medical pluralism" (ibid.: 50) of the Greek tradition in which the Hippocratic logos shared its power with the healing god Asclepius. Alternative and folk medicine have known an unprecedented revival in our digital era where everyone is eager to share their remedies on the internet. While this represents a challenge to the power of biomedicine and potentially makes different sources of knowledge accessible to patients, contemporary alternative medicine often turns into a lucrative and unscrupulous source of exploitation of the uncontrollable desires of sick people. When it not only complements, but also completely replaces medical logos, medical eros can become a self-destructive power.

An interesting attempt to conceive the collaboration between medical logos and medical eros as a way of empowering sick people and turning the illness experience into a tool for political struggle is represented by Audre Lorde's pathbreaking illness narrative The Cancer Journals (1980). A poet, Afro-American and lesbian activist, Lorde sets the example of a narrative that deeply connects the individual and social dimension of illness and existential and political transformation by making visible, and sharing, the traumatising consequences of the illness experience: "If we are to translate the silence surrounding breast cancer into language and action against this scourge, then the first step is that women with mastectomies must become visible to each other. For silence and invisibility go hand in hand with powerlessness" (Lorde 1980: 115).

One of the biggest challenges for the medical humanities today is how to propagate a more integrated and comprehensive view of illness and illness experience, a view that would contribute to reshaping "the nature, goals and knowledge base of clinical medicine" (Bolaki 2016: 8), raising at the same time patients' awareness of the possible risks of medical pluralism in the post-truth era of digital capitalism.

\section{THE ONLINE EXHIBITION}

This very brief and partial overview of the current state of the humanities research on the issue of illness reflected the conceptual basis of our 2020 seminar. The seminar was not conceived to present a systematic historical reconstruction of our ways of understanding illness. It rather attempted to explore specific issues comparing different works, often produced in different periods, in order to investigate constants and changes in our narrative, philosophical, visual, and political imagination about illness. 
In addition to reflecting on artistic works in different media which engage with different aspects of the illness experience, students were encouraged to submit their own creative works over the course of the semester. They used the opportunity to do so and produced a long and wide-ranging series of videos, blogs, artworks, short stories, podcasts, photographs, etc., based on their reflections about the material analysed in class as well as their personal experience of illness (see some examples in the figures below). The results were so interesting that we decided to make a selection of them available to the public in an online exhibition ${ }^{2}$ curated by graphic designer Jaana Davidjants. The exhibition can be freely visited until December 31, 2021. Many of the topics discussed above are reflected and rethought in the students' works, which, understandably, do not fail to address the current pandemic and the existential and social anxieties it brings.

\section{THE CONFERENCE}

The seminar culminated in a graduate conference, which took place on the 27th and 28th of January and offered the students an opportunity to present their final seminar papers to a wider audience. The variety of topics, objects and theoretical frameworks considered in the conference papers is a good index of the multiplicity and interdisciplinarity which characterise a humanities approach to the issue of illness.

The exploration of illness narratives which, as I have observed above, is a predominant issue in the medical humanities, was the central topic of a few papers too. In her analysis of the different narrative layers of the Awakenings, Hande Akiman reconstructed the changes occurring in the fifty-years' narrative about the surprising results of Oliver Sacks' experimentation with L-dopa on post-encephalitis lethargic patients. This narrative includes the letters and journal articles published by Sacks in the early 1970s, his book Awakenings (1973), the homonymous documentary (1973) and movie (1990), and the interviews and speeches that followed until Sacks' death in 2015. Akiman's analysis revealed the continuities, tensions and changes of this 'narrative about illness' through different genres, media, and perspectives. Natalie Arand focused on 'chaos narratives' and explored the fragmentation of the self in illness through a comparative analysis of Elyn Saks' memoir The Center Cannot Hold: My Journey Through Madness (2007), Richard Glatzer's movie Still Alice (2014), and Pablo Picasso's later self-portraits. The comparison of these representations of schizophrenia, Alzheimer's, and depression was based on the distinction between the fragmented self and the episodic self (Mackenzie \& Poltera 2010), the role of the Other, and the ethical aspects of mental illness narratives. In her paper on 
illness and the mind, Marlene Suits discussed coping techniques outside the biomedical framework in Camille Shooshani's documentary Léa \& I (2019), and Chuck Palahniuk's novel Fight Club (1996). Both works explore the instinctive and irrational medical desires of the protagonists as opposed to the dominant medical logos, although they present two opposite outcomes. In the documentary the search for alternative cures for fatal cystic fibrosis turns into a 'quest narrative' positively changing the protagonist who eventually finds the right balance between the medical eros and logos. In Fight Club, the failure of the erotic solution draws the protagonist into an alienating and self-destructive spiral.

Figure 1. Hannah Schaefer. "The puppeteer" (digital picture). A reflection on living with chronic cystitis.

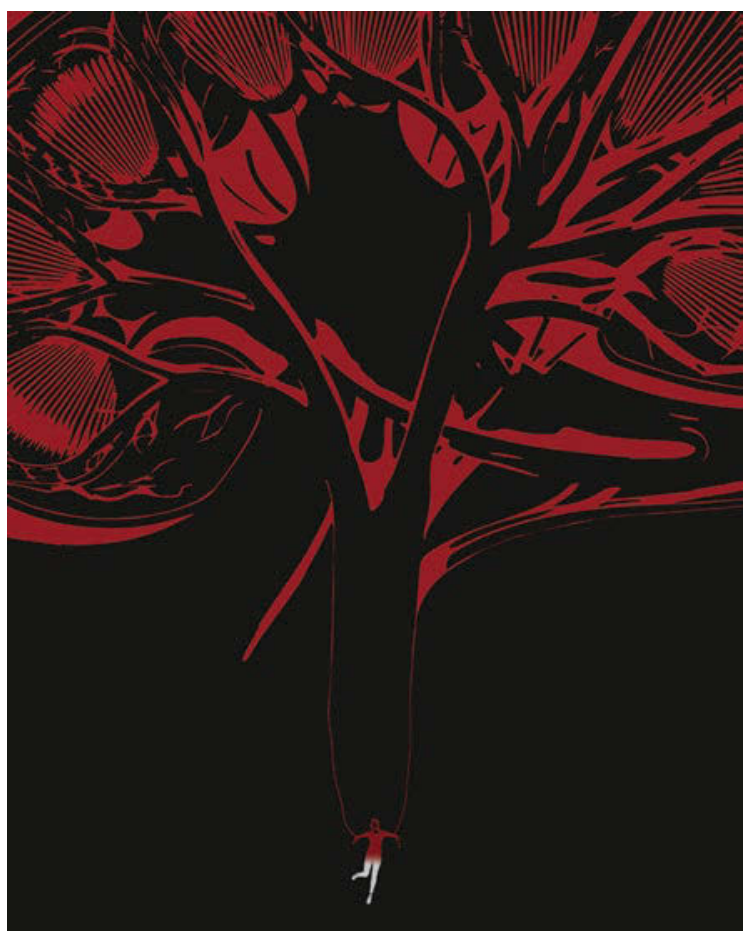

The issue of illness and alienation was a recurrent topic in the conference papers. Iveta Aare's paper also analysed Fight Club, although the focus of her attention was on the representation of the Dissociative Identity Disorder in the novel and in David Fincher's homonymous movie adaptation (1999). The paper showed how both authors use the narrative device of the unreliable narrator to create a character-centred illusion that becomes physical through Palahniuk's and Fincher's masterful use of chaotic narration, a mixture of actual dialogue and the protagonist's inner reflections and repeated allusions to the controversial nature of the characters. Eventually, the confusion caused in the process of reading/watching reminds us of the confusion experienced by the mentally 
ill person himself. Naz Özgen Üstünkaya explored the alienating effect of illness by comparing Sylvia Plath's novel The Bell Jar (1963) and Thea Sharrock's movie Me Before You (2016). The paper developed a close analysis of the protagonists in the novel and the movie and showed how, respectively, the bell jar of depression and the wheelchair of quadriplegia are made into symbols of the social isolation and self-estrangement of the protagonists. Suffering has no positively transformative effect here. It rather pushes the protagonists toward oblivion and self-annihilation, similarly to Fight Club. Marta Marita Lauri compared the depiction of radiation sickness and people affected by the atomic bombings of Hiroshima and Nagasaki in Ōta Yōko's novel City of Corpses (1948) and Ibuse Masuji's novel Black Rain (1965). In the novels the alienation provoked by illness is existential and individual as well as social and collective, and the narratives bring to the fore the tension between the suffering of the victims and the official discourse on the bombings. While in the City of Corpses writing coincides with the process of becoming sick and mirrors the confusion and frustration in the early post-war period, Black Rain dives into the past in order to affirm the right of suffering and to challenge the careful silence on the bombings in 1960s Japan.

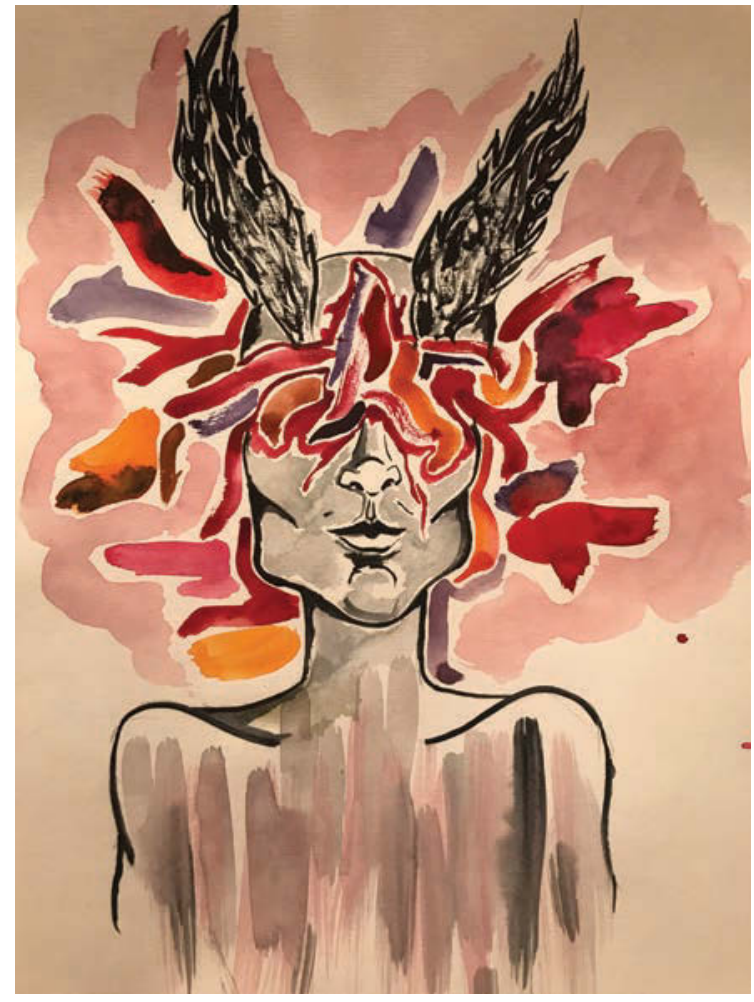

Figure 2. Iveta Aare. "A Midsummer Night's Dream”. A reflection on medical eros and Shannon Murphy's Babyteeth (2019). 


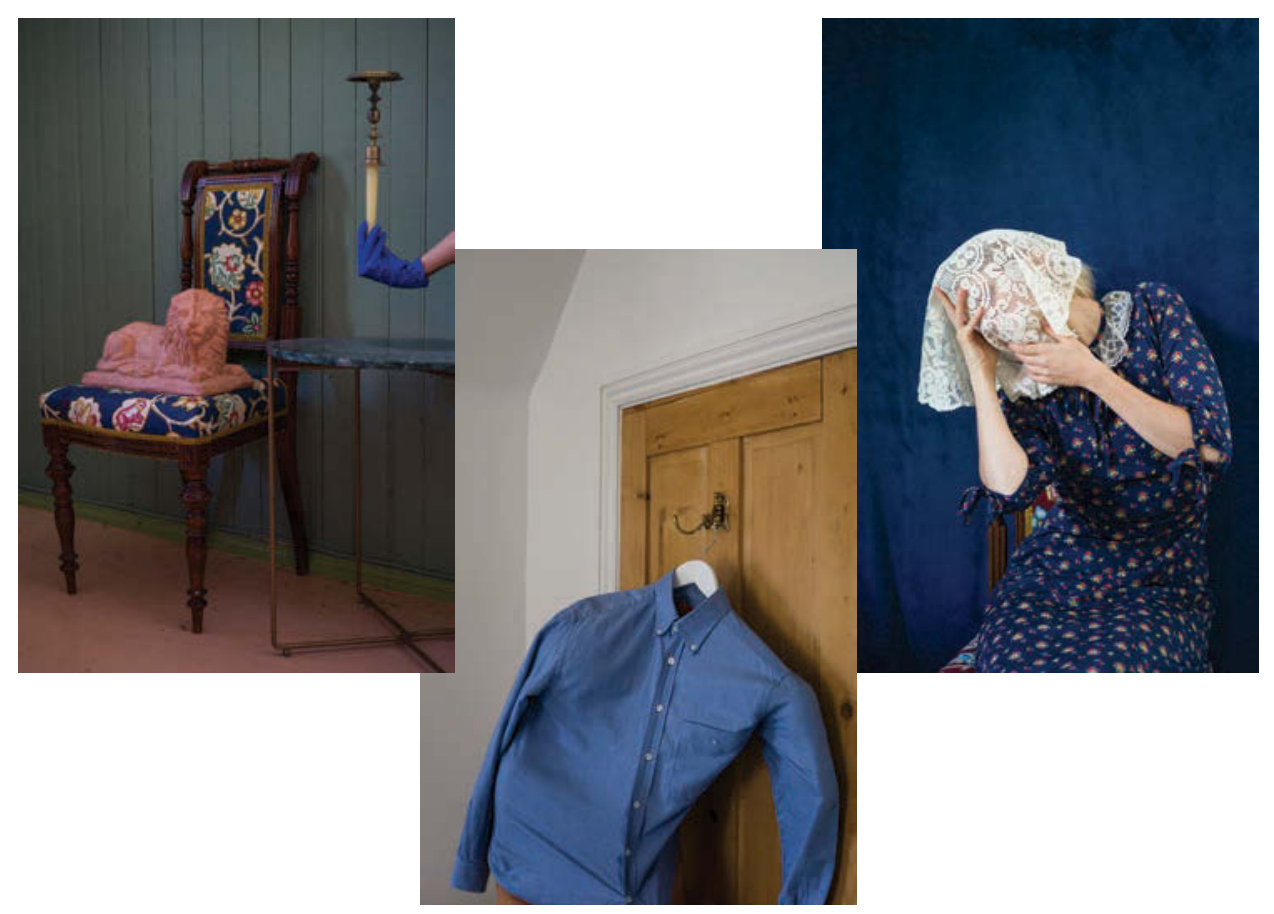

Figures 3-5. Mari Armei. "Blue Devils" (photo series). A reflection on melancholia.

The representation of illness and suffering in different media and arts has often been a means to reflect on the issues of human finitude and death. Mari Armei's paper adopted the perspective of phenomenology to investigate the transformative effect of terminal illness on one's being-in-the-world in Leo Tolstoy's novella The Death of Ivan Ilyich (1886) and Akira Kurosawa's movie Ikiru ('To Live', 1952). The radical changes in the bodies of the protagonists alter their relations with the world, turning it into an uncanny place. This starts a process of re-signification which in both cases transforms terminal illness into the access point to a more profound existential truth. A Heideggerian hermeneutical perspective on suffering and death was elaborated in the paper by Milani Perera, who compared Edgar Allan Poe's short story The Masque of the Red Death (1842) with Ingmar Bergman's movie The Seventh Seal (1957). While Tolstoy and Kurosawa represented individual illness, Poe's and Bergman's stories are set against the background of a lethal epidemic. Here being on the threshold of death does not bring about existential transformation. The social and political failure to properly deal with illness, suffering, and death results in an existential crisis (Bergman) or self-destructive denial (Poe). Michaela Dlouhá's paper followed continuities and changes in the theme of illness, suffering, and death 
in the work of Ingmar Bergman from Wild Strawberries (1957) and Persona (1966) to Cries and Whispers (1972) and Autumn Sonata (1978). While in the first movie the focus is on the world of a single sufferer on a journey through life towards death, Bergman's later works dig more complexly into the clash between the suffering worlds of different characters. The interaction between physical and psychological suffering, the dynamic of suffering within a family circle, the issues of maternity, care, and indifference thus acquire an increasingly important place in Bergman's mature reflection on illness.

While works on illness and finitude tend to focus on the individual level or the relations between people who are very close, and works on illness and alienation reflect in general more on the social norms that provoke additional psychological suffering for sick people, artistic representations of epidemics often take a more explicit political stance. This is particularly true of the representations of the AIDS epidemic, which was the topic of two conference papers. Mayra Lynn Assink proposed a queer perspective on AIDS through a comparison between the TV series POSE (2018-...) and Jeffrey Friedman and Rob Epstein's documentary film Common Threads: Stories from the Quilt (1989). Both narratives move between the levels of the individual, the community, and the institutions, challenging the established 'them vs us' binaries through which political discourse conceptualised the epidemic. These works of art are consequently able to add to the existing written history of the AIDS epidemic, transforming the perspective in which it was and is seen, narrated, and judged. The issue of visibility in personal narratives of the AIDS epidemic was explored by Ellie Power, who compared the use of sight and vision, the visible and the invisible in Felix Gonzales-Torres' billboard Untitled (1991) and Derek Jarman's documentary Blue (1993). Making invisible and obscuring visions of the bodies of their subjects, Gonzales-Torres and Jarman not only express their personal experience of the disease, but counter the wider political and societal reactions that condemn sufferers to invisibility and exclusion, the misinformation and fear that surrounded the disease having devastating consequences on those who were sick.

The visibility and exposure of sick and suffering bodies is an important political, ethical, and aesthetic issue in the representation of illness by the visual arts. What are the limits of the bearable? Who should decide? What kinds of reactions are these visualisations intended to provoke in the spectator, and what do they actually bring about? These are only some of the many questions that this particularly delicate aspect of illness narrative raises. Raya Bouslah's paper took the bull by the horns, exploring the evolution of representations of non-normative bodies in the history of cinema, asking how to film, how to look, and how (not) to react. In order to answer these questions, Bouslah compared Tod Browning's Freaks (1932), David Lynch's The Elephant Man (1980), and 
Aaron Schimberg's Chained for Life (2018). While the first two movies stimulate emotions of fear and pity, focusing on sensationalistic and superficial issues that do not fix the problem or even go as far as emphasising the idea of the other, Chained for Life manages to make the spectators critically face their inherited ideas about non-normative bodies through absurdity, meta-discourse, and the reversed roles that only film, as a visual medium, can offer. Anna Botalova approached the topic of the artistic representation of sick bodies through an analysis of pictures of lepers in medieval illuminated manuscripts. The status of leprosy and lepers was quite ambiguous in the medieval imagination. On the one hand, body deformity was thought to be a manifestation of soul's corruption, associated with sin or sexual misconduct. On the other hand, lepers as humble sufferers were considered closer to God, with compassion for the ill, helping Christians express their religious devotion, as the widespread artistic motif of 'kissing a leper' clearly shows. In Andreas Fecher's paper the 'revolting revolt' of suffering bodies is analysed from a semiotic perspective through a comparison of two movies which challenge the viewers with representations of terminal cancer: Peter Greenaway's The Belly of an Architect (1987) and Marian Dora's Carcinoma (2014). Fecher describes the protagonists' confrontation with the terminal disease as a semiotic crisis which forces them into a struggle with their own identity, conceptualised in the paper with the help of Yuri Lotman's understanding of the semiosphere and semiotic heterogeneity, and Julia Kristeva's concept of the pre-symbolic.

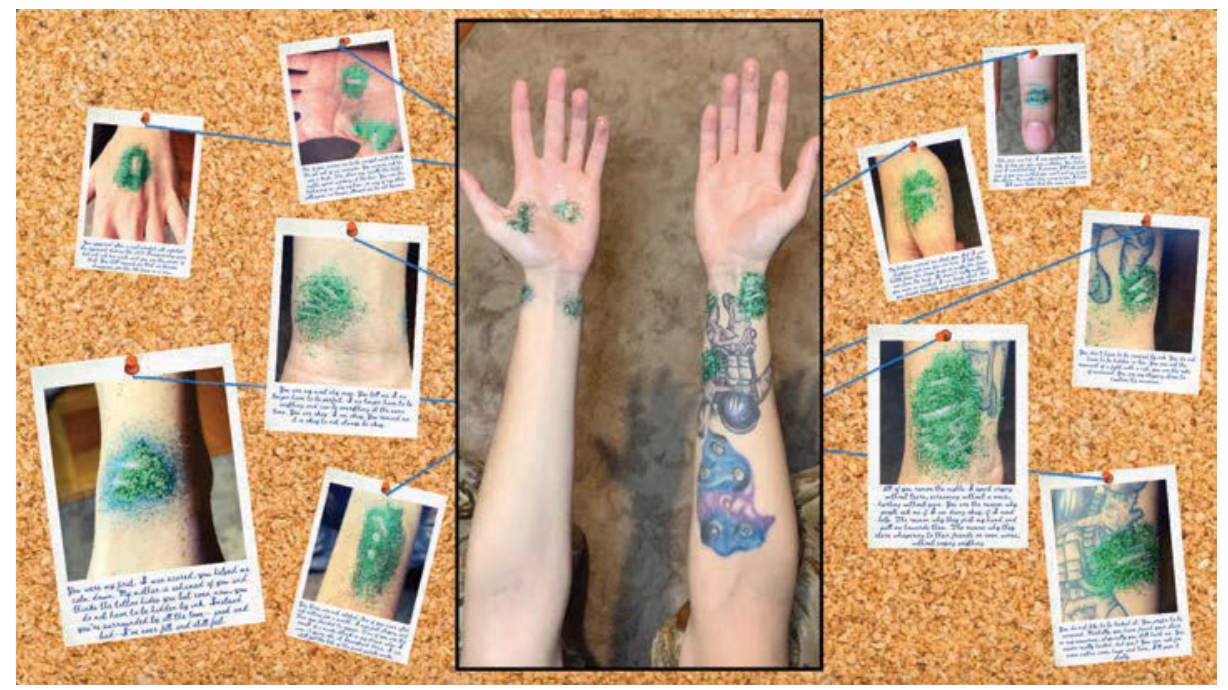

Figure 6. Mayra Lynn Assink. "The answers". A reflection on scars, memory, and viewpoints. 
In many of the works discussed so far sick bodies are represented in connection with gender and sexuality. For centuries these have been important categories in the cultural imagination about illness. The gender bias that takes the masculine body as the healthy norm, makes a dangerous source of sin and contamination of the feminine body, or a repository of a frail and helpless, sickly beauty to be protected and cherished. Femininity and illness are thus often related in the literature and art of the past and this stereotypical relation sadly resurfaces in many phenomena of contemporary popular as well as high culture. Pierangelly Del Rio Martinez investigated one of the most pernicious gendered stereotypes about illness, that which depicts hysteria as an essentially feminine disease. Her paper developed a feminist approach to two American autobiographical fiction works, Charlotte Perkins Gilman's The Yellow Paper (1892) and Sylvia Plat's The Bell Jar (1963). Both texts offer instruments for a critique of medical diagnoses and treatments which deprive women of their essential needs and forbid them from actively participating in their recovery. And both authors try to regain a sense of agency in the midst of illness by the act of writing their accounts. Jonas Henrik Holm Pedersen's paper described and deconstructed another stereotypical conjunction of illness with femininity, the 19th-century aesthetic topos of the femme fragile. Pedersen analysed John William Waterhouse's painting The Lady of Shalott (1888) as a prototypical representation of the fragility of a woman materialised through illness as symbolic of her godliness and purity. Princess Fiona, from Andrew Adamson and Vicky Jenson's animated film Shrek (2001), was used in the paper to subvert the typical imagination of the femme fragile, as the curse and illness which are usually the cause of femme fragile's eventual demise become the means of Fiona's empowerment in the movie.

This brief overview of the conference papers clearly shows that the attention of the participants focused mainly on first person illness narratives and on documentaries and fiction with an autobiographical background, or on cultural representation of illness from an external, third person position. Only two papers explicitly focused on doctors as fundamental shapers of illness processes and narratives. I started my overview with Akiman's paper on neurologist Oliver Sacks' fifty-years' construction, deconstruction, and reconstruction of the awakenings narrative, and I will finish it with Margherita Marchetti's paper comparing doctor Gregory House from the TV series House M.D. (2004-2012) with Sherlock Holmes from the TV series Sherlock (2010-2017). Marchetti showed how medicine and criminology share the same ambition of revealing the unknown through a pattern of clues that give access to deeper knowledge. Both characters exemplify the ambiguous relationship with the pharmakon, which according to Jacques Derrida (1968) is at the same time both a remedy and a poison. Their addiction to mystery and solution seeking specifically leads 
House and Sherlock to drug addiction, keeping the discussion about medicine and criminology open.

If illness is, as Susan Sontag claimed, the night side of life, the seminar, exhibition, and conference reviewed above offered their modest contribution to shedding some light on the way in which that night has been represented and understood by the arts and humanities at different times and in different cultures. The present pandemic has uncontestably revealed the complexity of the illness phenomenon. An adequately comprehensive academic approach to such complexity would include a long list of disciplines from virology to psychology, from anthropology and cultural studies to law, from political science to philosophy, from economy to demography, etc. Such an open multidisciplinary domain should be supplemented by the historical perspective which not only allows us to unravel the causes of the present situation, but also to become aware of the fact that nothing is quite new under the sun and that we have a lot to learn from the past, as the literary and historical chronicles of real and fictional epidemics clearly show (see Monticelli 2021). The humanities are in a privileged position to address the multidisciplinary complexity of the illness phenomenon, as well as the historical developments and comparisons required to understand it more adequately. And, as humanities scholars, we have to take responsibility for promoting, even in the bleakest of times, trust in the transformative potential of research at the individual as well as the collective level of our existences.

\section{NOTES}

1 If we take internet coverage as a litmus paper of the global impact of social phenomena, Google currently offers over 5 billion search responses for Covid-19 and 'only' 1.5 billion for AIDS (as of 25th March 2021).

2 See https://illnessnarratives2021.cargo.site/, last accessed on 5 May 2021.

\section{REFERENCES}

Bertman, Martin A. 1978. The Natural Body and the Body Politic. Philosophy \& Social Criticism, Vol. 5, No. 1, pp. 18-34. http://dx.doi.org/10.1177/019145377800500102.

Bolaki, Stella 2016. Illness as Many Narratives: Arts, Medicine and Culture. Edinburgh: Edinburgh University Press.

Charmaz, Kathy 1983. Loss of Self: A Fundamental Form of Suffering in the Chronically Ill. Sociology of Health and Illness, Vol. 5, No. 2, pp. 168-195. http://dx.doi. org/10.1111/1467-9566.ep10491512.

Derrida, Jacques 1968. La pharmacie de Platon. Tel Quel, Vol. 32, pp. 257-403.

Foucault, Michel 2003. The Birth of the Clinic. London \& New York: Routledge. 
Frank, Arthur W. 1995. The Wounded Storyteller: Body, Illness, and Ethics. Chicago \& London: The University of Chicago Press.

Hawkins, Anne Hunsaker 1999. Reconstructing Illness: Studies in Pathography. West Lafayette, IN: Purdue University Press.

Hope, Valerie M. \& Marshall, Eireann (eds.) 2004 [2000]. Death and Disease in the Ancient City. London \& New York: Routledge.

Hyden, Lars-Christer 1997. Illness and Narrative. Sociology of Health and Illness, Vol. 19, No. 1, pp. 48-69. http://dx.doi.org/10.1111/j.1467-9566.1997.tb00015.x.

Lorde, Audre 1980. The Cancer Journals. San Francisco: Aunt Lute Book.

Mackenzie, Catriona \& Poltera, Jacqui 2010. Narrative Integration, Fragmented Selves, and Autonomy. Hypatia, Vol. 25, No. 1, pp. 31-54. http://dx.doi.org/10.1111/j.15272001.2009.01083.x.

Monticelli, Daniele 2021. Katkulugude lühilugu: metafoorid, narratiivid, poliitika. [Short History of Plague Stories: Metaphors, Narratives, Politics.] Vikerkaar, No. 1-2, pp. 84-98. Available at https://www.vikerkaar.ee/archives/26914, last accessed on 5 May 2021.

Morris, David B. 2017. Eros and Illness. Cambridge, MA: Harvard University Press.

Radley, Alan 1999. The Aesthetics of Illness: Narrative, Horror and the Sublime. Sociology of Health \& Illness, Vol.21, No. 6, pp.778-796. http://dx.doi.org/10.1111/1467-9566.00183.

Rosenberg, Charles E. 1989. What is an Epidemic? AIDS in Historical Perspective. Dedalus, Vol. 118, No. 2. Special issue: Living with AIDS, pp. 1-17. Available at https://www.jstor.org/stable/20025233?seq=1\#metadata_info_tab_contents, last accessed on 5 May 2021.

Sontag, Susan 1978. Illness as Metaphor. New York: Ferrar, Straus and Giroux.

Sontag, Susan 1989. AIDS and Its Metaphors. New York: Farrar, Straus and Giroux.

Wald, Priscilla 2008. Contagion: Cultures, Carriers, and the Outbreak Narrative. Durham \& London: Duke University Press.

Whitehead, Lisa Claire 2005. Quest, Chaos and Restitution: Living with Chronic Fatigue Syndrome/Myalgic Encephalomyelitis. Social Science \& Medicine, Vol. 62, No. 9, pp. 2236-2245. http://dx.doi.org/10.1016/j.socscimed.2005.09.008.

Woolf, Virginia 1926. On Being Ill. The New Criterion, Vol. 4, No. 1, pp. 32-45. Available at https://thenewcriterion1926.files.wordpress.com/2014/12/woolf-on-being-ill.pdf, last accessed on 5 May 2021.

Daniele Monticelli $(\mathrm{PhD})$ is a translation scholar and semiotician. His research focuses on cultural transfer and translation in history with particular attention to the role of translation in the construction and deconstruction of national identities in Central and Eastern Europe at the end of the 19th and the beginning of the 20th centuries, translation, power, and censorship under communism; political thought in contemporary critical theory (G. Agamben, A. Badiou, J. Rancière); and the theoretical legacy of the later works of Yuri Lotman. Monticelli currently works as a professor of translation studies and semiotics at Tallinn University, Estonia, and is the project leader of the Estonian Research Council PRG grant "Translation in History, Estonia 1850-2010: Texts, Agents, Institutions and Practices".

daniele.monticelli@tlu.ee 